\title{
Total glucosides of paeony ameliorates oxidative stress, apoptosis and inflammatory response by regulating the Smad7-TGF- $\beta$ pathway in allergic rhinitis
}

\author{
YANGZI JIN and AICHUN ZHANG \\ Department of Otolaryngology, The First Affiliated Hospital of \\ Zhejiang Chinese Medical University, Hangzhou, Zhejiang 310000, P.R. China
}

Received May 21, 2021; Accepted November 29, 2021

DOI: $10.3892 / \mathrm{mmr} .2022 .12599$

\begin{abstract}
Total glucosides of paeony (TGP), an active ingredient extracted from the root of Paeonia alba, has been reported to display an anti-inflammatory effect. However, the effect of TGP on allergic rhinitis (AR) is still unknown. The present study aimed to assess the role of TGP in an AR mouse model. An AR mouse model was established using the ovalbumin method. The expression levels of Smad7/TGF- $\beta$ pathway-related prtoeins in nasal mucosa tissues were determined by immunofluorescence, immunohistochemistry and western blotting. The severity of nasal allergic symptoms was detected by recording the frequency of sneezing and nose rubbing motions in all mice for $20 \mathrm{~min}$. The levels of $\operatorname{IgE}$ and inflammatory cytokines, including IL-4, IL-5, IL-17 and IFN- $\gamma$, in the serum were measured by conducting ELISAs. H\&E staining, periodic acid-Schiff staining and Masson staining were used to detected histopathological changes in mice. The concentrations of malondialdehyde and glutathione, and the activities of superoxide dismutase and catalase in tissue supernatant and serum were quantified using commercial assay kits. Apoptosis of nasal tissue cells was detected by performing TUNEL assays and western blotting. The expression of Smad7 was upregulated and that of TGF- $\beta$ was downregulated in the nasal tissue of AR mice. Additionally, TGP regulated the Smad7/TGF- $\beta$ pathway in the nasal tissue of AR mice. TGP alleviated serum IgE, nasal symptoms and histopathological changes in AR mice. Moreover, TGP ameliorated oxidative stress, cell apoptosis and inflammatory response. Smad7 small interfering RNA intervention aggravated the symptoms of AR mice via activation of the TGF- $\beta$ pathway and reversed
\end{abstract}

Correspondence to: Dr Aichun Zhang, Department of Otolaryngology, The First Affiliated Hospital of Zhejiang Chinese Medical University, 54 Youdian Road, Shangcheng, Hangzhou, Zhejiang 310000, P.R. China

E-mail: aichunzhangmrs@163.com

Key words: allergic rhinitis, total glucosides of paeony, Smad7-TGF- $\beta$ pathway, inflammatory response the protective effect of TGP in AR mice. TGP ameliorated oxidative stress, apoptosis and inflammatory response via the Smad7/TGF- $\beta$ pathway in AR.

\section{Introduction}

Allergic rhinitis (AR) is a non-communicable chronic inflammatory disease of the nasal mucosa mediated by immunoglobulin $\mathrm{E}(\mathrm{IgE})$. AR is caused by exposure of genetically susceptible individuals to environmental allergens (1). The prevalence of AR has increased worldwide, affecting 10-40\% of the global population (2,3); in China, AR incidence has been reported to range from 8.7 to $24.1 \%$ of the population (4). AR is also associated with a variety of complications, including asthma and otitis media, which affect quality of life and work performance, and imposes a financial burden (3,5). Currently, corticosteroids and antihistamines (H1 receptor blockers) are used for AR treatment (6-8). Although glucocorticoids are the most effective drug for most patients at present, systemic side effects limit their use in large doses over long periods of time (9). Moreover, glucocorticoids do not cure AR since a rebound phenomenon occurs following drug withdrawal. Antihistamines can attenuate sneezing, itching and runny nose, but have no effect on congestion (10). Furthermore, anticholinergic side effects including drowsiness, sedation and somnolence, and depression are associated with multiple antihistamine treatment $(6,11)$. Therefore, providing a novel strategy derived from natural products that are safe and effective for AR therapy is of practical importance.

Total glucosides of paeony (TGP) is an active ingredient extracted from the root of Paeonia alba that is characterized by anti-inflammatory, anti-oxidative and pain-relieving properties $(9,12)$. In addition, TGP regulates the balance of the $\mathrm{T}$ helper (h)1/Th2 ratio via two-way cellular immune regulation, which induces reverse modulation of $\mathrm{B}$ lymphocyte growth (13). TGP has been reported to serves an important role in the treatment of both inflammatory and immune disease (14-16). Previous studies have shown that the pathogenesis of AR is type I allergic disease caused by Th1/Th2 immune imbalance, accompanied by Th17, T regulatory and other Th cell participation $(10,17)$, indicating that TGP may have a therapeutic effect on AR. 
$\mathrm{AR}$ is an inflammatory disease with complex pathogenesis involving a variety of signaling cascades and regulatory pathways (18). To the best of our knowledge, its molecular mechanism has not yet been elucidated. The transforming grow th factor- $\beta$ (TGF- $\beta$ ) family has been reported to serve a critical role in inflammatory and immune response regulation $(19,20)$. Evidence suggests that the immunoreactivity of the TGF- $\beta$ signal pathway is enhanced along with increased nasal mast cells in AR (21), suggesting TGF- $\beta$ signaling may be involved in AR pathogenesis. As an inhibitor of TGF- $\beta$ signaling, Sma- and Mad-related protein 7 (Smad7) blocks TGF- $\beta 1$-triggered signaling by binding to the TGF- $\beta$ receptor to mediate biological activity of TGF- $\beta 1$ and affect airway remodeling (22). Therefore, it was hypothesized that TGP ameliorates the symptoms of AR by regulating the Smad7-TGF- $\beta$ signaling pathway.

The present study aimed to provide insight into the effect of TGP in an AR mouse model by investigating the Smad7/TGF- $\beta$ signaling pathway to elucidate the potential mechanism underlying the role of TGP and propose an optimal therapeutic strategy for AR.

\section{Materials and methods}

Animals. A total of 88 specific-pathogen-free BALB/c male mice (age, 6 weeks; weight, 20-22 g) were obtained from Jinan Pengyue Laboratory Animal Breeding Co., Ltd. (Jinan, China; Research Resource Identifier SCR_010607). All mice were accommodated at an average temperature of $22 \pm 2^{\circ} \mathrm{C}$ with $55 \pm 10 \%$ humidity in a controlled habitat with a 12 -h light/dark cycle (light on 8:00 a.m.-8:00 p.m.). In addition, free access to standard food and water was provided. All experimental procedures performed on animals were based on the National Institutes of Health Guide for the Care and Use of Laboratory Animals (23) and the study was approved by the Institutional Animal Care and Use Committee of the First Affiliated Hospital of Zhejiang Chinese Medical University (approval no. AWE2020030601). All efforts were made to minimize the suffering of animals.

Construction of AR mouse model. Mice used to establish the AR model were sensitized via intraperitoneal injection of $75 \mu \mathrm{g}$ ovalbumin (OVA; Sigma-Aldrich; Merck KGaA) diluted in $200 \mu \mathrm{l}$ sterile normal saline supplemented with $2 \mathrm{mg}$ aluminum hydroxide (Sigma-Aldrich; Merck KGaA). Diluted OVA (total volume, $200 \mu \mathrm{l}$ ) was injected into the mice on days $0,7,14$ and 21 , respectively. Subsequently, mice were challenged with daily nasal instillation of $500 \mu \mathrm{g}$ OVA diluted in $20 \mu \mathrm{l}$ sterile saline on days 23-27 after initial sensitization. For the AR control (con), challenge with OVA was replaced by challenge by sterile saline.

Study grouping. A total of 88 mice were randomly assigned into seven groups ( $\mathrm{n}=8$ /group) as follows: i) Con (untreated); ii) AR (OVA-induced AR); iii) $\mathrm{AR}+$ saline (AR mice given $60 \mathrm{mg} / \mathrm{kg}$ saline orally); iv) AR $+10 \mathrm{mg} / \mathrm{kg}$ TGP (AR mice given $10 \mathrm{mg} / \mathrm{kg}$ TGP orally); v) AR + $20 \mathrm{mg} / \mathrm{kg}$ TGP (AR mice given $20 \mathrm{mg} / \mathrm{kg}$ TGP orally); vi) $\mathrm{AR}+30 \mathrm{mg} / \mathrm{kg}$ TGP (AR mice given $30 \mathrm{mg} / \mathrm{kg}$ TGP orally); vii) $\mathrm{AR}+60 \mathrm{mg} / \mathrm{kg}$ TGP (AR mice given $60 \mathrm{mg} / \mathrm{kg}$ TGP orally); viii) $\mathrm{AR}+120 \mathrm{mg} / \mathrm{kg}$
TGP (AR mice given $120 \mathrm{mg} / \mathrm{kg}$ TGP orally); ix) AR + small interfering (si)-con (AR mice injected with $60 \mu \mathrm{g} / \mathrm{kg}$ siRNA negative con vector via the caudal vein); $\mathrm{x}) \mathrm{AR}+\mathrm{si}-\mathrm{Smad} 7$ (AR mice injected with $40 \mu \mathrm{g} / \mathrm{kg}$ Smad7 siRNA vector via the caudal vein) and $\mathrm{xi}$ ) AR + TGP + si-Smad7 (AR mice given $60 \mathrm{mg} / \mathrm{kg}$ TGP orally and injected with $40 \mu \mathrm{g} / \mathrm{kg} \mathrm{Smad} 7$ siRNA via the caudal vein).

After grinding TGP (H20055058; Ningbo Lihua Pharmaceutical Co., Ltd.) into powder, $10 \mathrm{mg} / \mathrm{ml}$ suspension was prepared with $0.5 \%$ sodium carboxymethyl cellulose. For the TGP treatment groups, mice were administered $60 \mathrm{mg} / \mathrm{kg}$ TGP orally after daily intranasal challenge on days 28-42, while an equal volume of saline instead of TGP was given to mice in the saline groups. The siRNA negative con (forward, 5'-UUCUCCGAACGUGUCACG-UTT-3' and reverse, 5'-ACGUGACACGUUCGGAGAATT-3') and Smad7 siRNA vectors (forward, 5'-CCAAUGACCACGAGUUUA-UTT-3' and reverse, 5'-AUAAACUCGUGGUCAU-UGGTT-3') were designed and constructed by Shanghai GenePharma Co., Ltd.

Measurement of nasal symptoms. Following the final OVA/sterile saline challenge on day 27 post-initial sensitization, the severity of nasal allergic symptoms was detected by recording the frequency of sneezing and nose rubbing motions in all mice for $20 \mathrm{~min}$. Measurement of nasal symptoms was performed in a single-blinded manner by three experimenters.

Blood and tissue samples. At the end of the experiment, mice in each group were fasted overnight and anesthetized with intraperitoneal injection of sodium pentobarbital $(50 \mathrm{mg} / \mathrm{kg}$ body weight). The mice were sacrificed by cervical dislocation following deep anesthesia. Blood $(0.5 \mathrm{ml})$ was harvested from the abdominal aorta into tubes with EDTA followed by centrifugation at $1,000 \mathrm{x}$ g for $20 \mathrm{~min}$ at $4^{\circ} \mathrm{C}$ to prepare plasma for the biochemical analysis. The nasal mucosa was removed immediately and rinsed with cold saline before preserving at $-70^{\circ} \mathrm{C}$. Half of the nasal mucosa tissue was fixed in $4 \%$ paraformaldehyde for $24 \mathrm{~h}$ at room temperature and then embedded in paraffin, followed by slicing into $5 \mu \mathrm{m}$ sections for histological examination. Cold Tris- $\mathrm{HCl}(10 \mathrm{mM})$ was used to homogenize the rest of the tissue immediately, and clear supernatant was obtained by centrifuging at 4,000 $\mathrm{x}$ for $10 \mathrm{~min}$ at $4^{\circ} \mathrm{C}$ for use in biochemical analysis.

Immunofluorescence. The nasal mucosa slices were dehydrated and dewaxed followed by treatment with $3 \%$ hydrogen peroxide for $10 \mathrm{~min}$ at room temperature to quench the endogenous peroxidase activity. Then, $10 \%$ goat serum (cat. no. 5425S; Cell Signaling Technology, Inc.) and 0.3\% Triton X-100 PBS solution were used to block the slices for $1 \mathrm{~h}$ at room temperature, followed by culturing with primary antibodies [Smad7 (cat.no. ab272928; 1:100) and TGF- $\beta$ (cat. no. ab15537; $5 \mu \mathrm{g} / \mathrm{ml}$ ); both Abcam] overnight at $4^{\circ} \mathrm{C}$. Subsequently, corresponding fluorescent-labeled secondary antibody (cat. no. ab150117; 1:200; Abcam) was used to treat the slices for $1 \mathrm{~h}$ at room temperature. To identify the nuclei, $5 \mu \mathrm{g} / \mathrm{ml}$ DAPI (Invitrogen; Thermo Fisher Scientific, Inc.) was used to stain the slices for $5 \mathrm{~min}$ at room temperature. Finally, a fluorescence microscope (Olympus Corporation; cat. no. BX 51; magnification, x200) was used to observe Smad7- and TGF- $\beta$-positive cells in the 
nasal mucosa slices. Data were evaluated by Image ProPlus version 5.0 software (Media Cybernetics, Inc.).

Immunohistochemistry. For immunohistochemistry assay, xylene was used to dewax nasal mucosa tissue slices, which were then rehydrated followed by dehydrating in graded ethanol solution. Slices were heated with citrate $(10 \mathrm{mmol} / \mathrm{l}$, $\mathrm{pH}$ 6.0) in a microwave for $30 \mathrm{~min}$ for antigen retrieval. To block the endogenous peroxidase activity, $0.3 \%$ hydrogen peroxide solution was utilized to incubate the slices for $30 \mathrm{~min}$ at room temperature. Following $5 \mathrm{~min}$ washing in PBS, the slices were cultured with primary antibody against Smad7 (cat. no. ab216428, 1:100, Abcam,) and TGF- $\beta$ (cat. no. ab15537, 1:100, Abcam) at $4^{\circ} \mathrm{C}$ overnight, then treated with horseradish peroxidase (HRP)-conjugated secondary antibody (cat. no. ab6721, 1:1,000, Abcam,) for $30 \mathrm{~min}$ at room temperature. Finally, 3, 3'-diamino-benzidine tetrahydrochloride was used to develop the signal for visualization of positive cells for examination under a light microscope (Zeiss $\mathrm{GmbH}$; magnification, x500;). Data were evaluated using Image ProPlus version 5.0 software (Media Cybernetics, Inc.).

Western blot analysis. RIPA lysis buffer (Beyotime Institute of Biotechnology) supplemented with protease inhibitors was utilized to obtain total protein from nasal tissue homogenate and the concentration was determined by bicinchoninic acid assay (BCA) kit (Pierce; Thermo Fisher Scientific, Inc.). Subsequently, equal amounts of total protein $(30 \mathrm{mg} / \mathrm{lane})$ were isolated by $10 \%$ sodium dodecyl sulfate polyacrylamide gel electrophoresis followed by wet transfer onto PVDF membranes (MilliporeSigma). Then, 5\% non-fat milk diluted in TBST $(0.1 \%$ Tween-20) was used to block the membranes for $1 \mathrm{~h}$ at room temperature, followed by treatment with rabbit primary antibodies against Smad7 primary (cat. no. ab227309, 1:500; Abcam), TGF- $\beta$ (cat. no. ab205604, 1:1,000; Abcam), Bax (cat. no. ab182733; 1:2,000; Abcam), Bcl-2 (cat. no. ab32124, 1:1,000; Abcam), Cleaved-caspase 3 (cat. no. ab2302, 1:200; Abcam), IL-4 (cat. no. ab62351, 1:2,000; Abcam), IL-5 (cat. no. 3432, 1:1,000; Cell Signaling Technology, Inc.), IL-17 (cat. no. 13828, 1:2,000; Cell Signaling Technology, Inc.), IFN- $\gamma$ (cat. no. 8455, 1:1,500; Cell Signaling Technology, Inc.) and $\beta$-actin (cat. no. ab8227; 1:1,000; Abcam) at $4^{\circ} \mathrm{C}$ overnight. Membranes were rinsed with PBS for $5 \mathrm{~min}$ and incubated with appropriate HRP-conjugated secondary antibody IgG (cat. no. ab15842, 1:1,000; Abcam) for $1 \mathrm{~h}$ at room temperature. Protein bands were developed with ECL detection reagent (Thermo Fisher Scientific, Inc.) and the band intensity was quantified using Image $\mathrm{J}$ software (National Institutes of Health; version 1.44o). $\beta$-actin was used as the internal control to normalize the relative levels of protein.

Measurement of $\operatorname{IgE}$ and inflammatory cytokines in serum. The levels of IgE and inflammatory cytokines in the plasma of each mouse were measured by ELISA. ELISA kits (R\&D System) were utilized to determine the levels of IL-4 (cat. no. PI612; Beyotime Institute of Biotechnology), IL-5 (cat. no. PI620; Beyotime Institute of Biotechnology), IL-17 (cat. no. PI545; Beyotime Institute of Biotechnology), IFN- $\gamma$ (cat. no. PI508; Beyotime Institute of Biotechnology) and IgE (cat. no. 747734; Pharmingen) in the serum according to the manufacturer's protocol. Following washing by PBS, plasma was treated with HRP and chromogenic solution of biotin. Finally, absorbance at $450 \mathrm{~nm}$ was measured.

Histopathological evaluation of nasal mucosa tissue. For histopathological evaluation of nasal mucosa tissue, hematoxylin-eosin (HE) staining was performed to measure the number of eosinophils, periodic acid-Schiff (PAS) staining was used to detect the number of goblet cells and Masson staining was performed to determine the percentage of collagen fibers. Briefly, nasal mucosa tissue slices underwent dewaxing, rehydration and dehydration followed by staining with HE, PAS and Masson's trichrome reagent in accordance with the manufacturer's instructions. (all Sigma-Aldrich; Merck $\mathrm{KGaA}$ ). Numbers of eosinophils and goblet cells, as well as the percentage of collagen fibers were observed and quantified using Image-Proplus 6.0 (Media Cybernetics, Inc.) under a light microscope (Zeiss $\mathrm{GmbH}$ ) in five randomly selected fields of view at 500x magnification. The histopathological changes in each group were assessed in a double-blind manner. Eosinophils and gobletells are presented as number $/ \mathrm{mm}^{2}$ per section, while collagen fibers are expressed as a percentage.

Oxidative stress detection. The concentration of malondialdehyde (MDA) and glutathione (GSH), and activity of superoxide dismutase (SOD), and catalase (CAT) in the nasal mucosa tissue and serum were determined as previously described (20). A homogenizer was used to prepare $100 \mathrm{~g} / 1$ tissue homogenate from fresh nasal mucosa tissue, followed by centrifugation at $4,000 \mathrm{x}$ g for $20 \mathrm{~min}$ at $4^{\circ} \mathrm{C}$. BCA protein assay kit was used to quantify the protein concentration in tissue using the appropriate amount of supernatant $(20 \mu \mathrm{l})$. In accordance with the manufacturer's protocol, the concentrations of MDA and GSH, and the activities of SOD and CAT in tissue supernatant and serum were measured using MDA kit (cat. no. S0131), SOD (cat. no. S0109), GSH (cat. no. S0052) and CAT kits (cat. no. C0016; all Beyotime Institute of Biotechnology), respectively. The concentrations of MDA and GSH are presented in $\mathrm{nmol} / \mathrm{mg}$ protein, while the activity of SOD and CAT are presented in $\mathrm{U} / \mathrm{mg}$ protein.

TUNEL staining. Apoptosis of nasal tissue cells was detected by TUNEL assay using an In Situ Cell Death Detection kit (cat. no. 11684795910; Roche Diagnostics GmbH) according to the manufacturer's protocol. Briefly, following deparaffinization of nasal tissue slices with gradient alcohol, DNA fragments were stained using the In Situ Cell Death Detection kit according to the manufacturer's instructions. Then, a confocal microscope (Leica-Leitz DM-Il; Leica Microsystems $\mathrm{GmbH}$ ) was used to observe the stained sections at $\times 200$ magnification. To evaluate apoptosis, five fields of view were randomly selected to count TUNEL-positive cells and analyzed using Image-Pro Plus 6.0 (Media Cybernetics, Inc.) to quantify the apoptosis rate.

Statistical analysis. Data are expressed as the mean \pm standard deviation of three experimental repeats. All statistical analysis was performed utilizing SPSS 21.0 statistical software (IBM Corp). Data with non-normal distribution was 
A

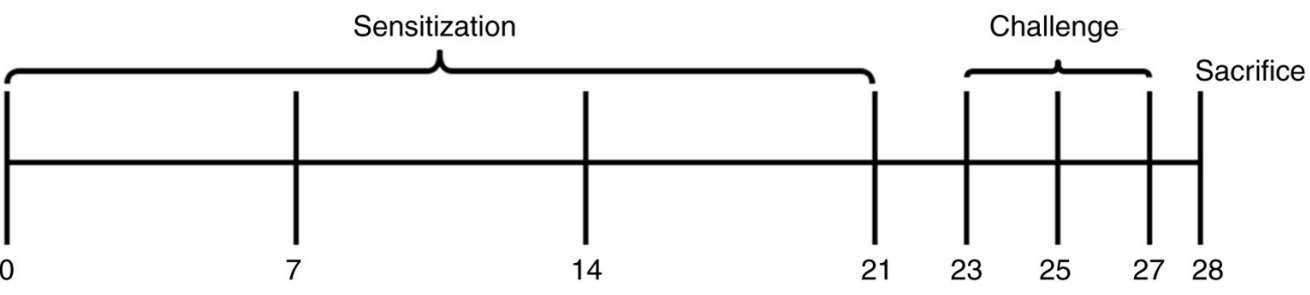

B

B $\quad$ Smad7
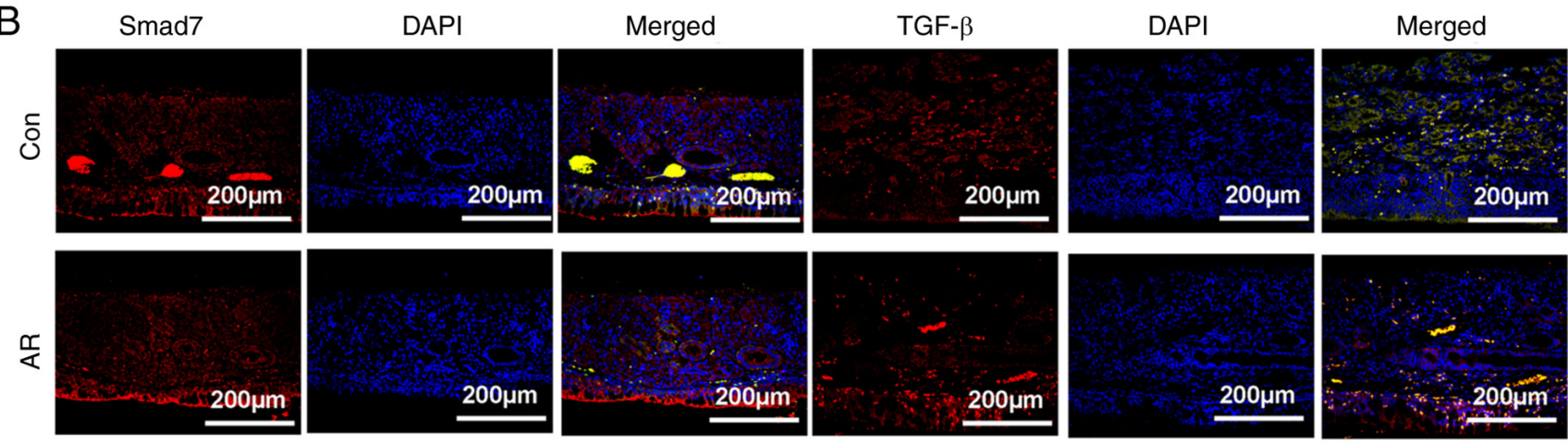

C

Con

AR

Con

AR
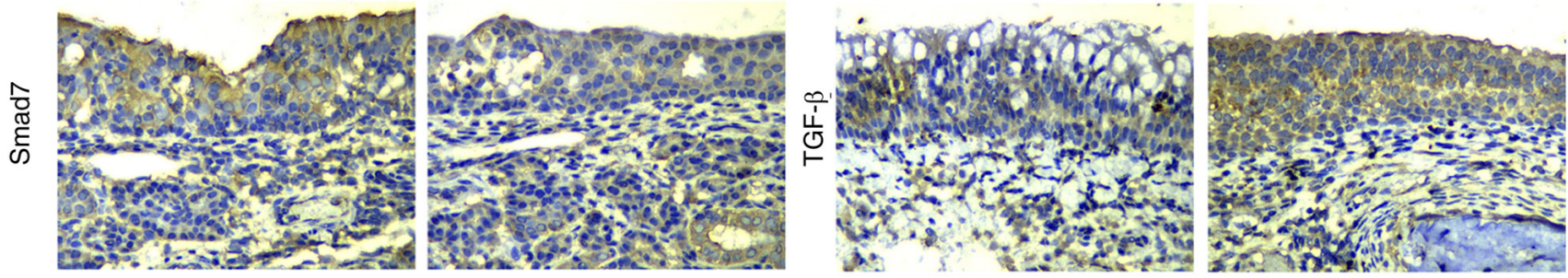

D
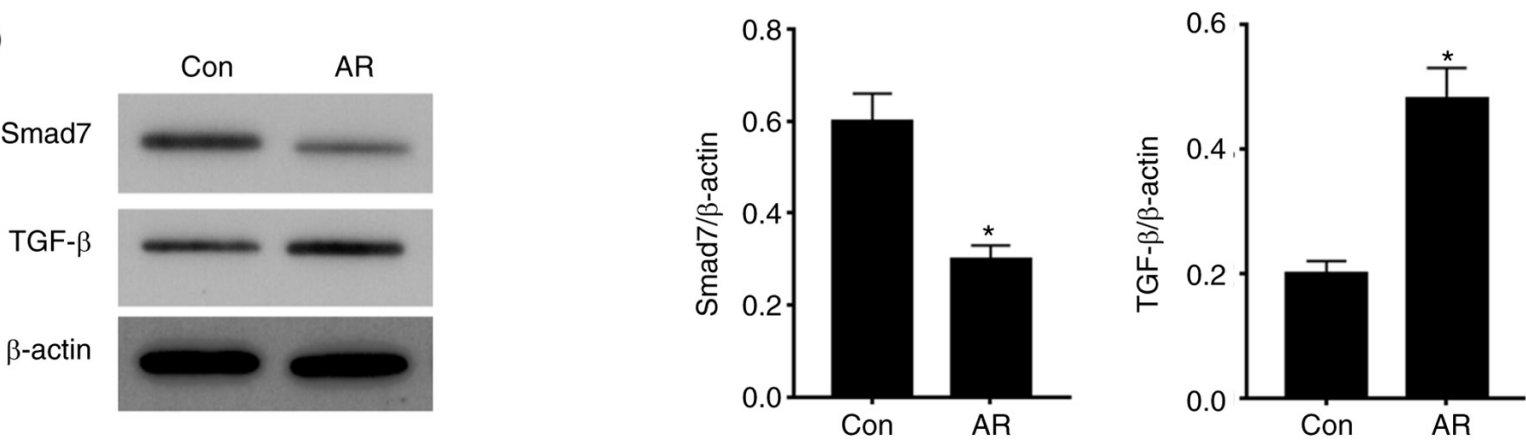

Figure 1. Expression of Smad7/TGF- $\beta$ pathway-associated protein in nasal tissue of AR mice. (A) Schematic diagram of the experimental group design and protocol for AR mice. (B) Expression levels of Smad7 and TGF- $\beta$ were measured by immunofluorescence assay. Protein expression levels of Smad7 and TGF- $\beta$ were measured by (C) immunohistochemistry and (D) western blot analysis. "P<0.05 vs. Con. Smad7, Sma- and Mad-related protein 7; AR, allergic rhinitis; Con, control.

analyzed by Mann-Whitney U test. For the data with normal distribution, differences between two groups were analyzed by unpaired Student's t-test; comparisons between $\geq 3$ groups were analyzed by one-way ANOVA followed by post hoc Tukey's test. $\mathrm{P}<0.05$ was considered to indicate a statistically significant difference.

\section{Results}

Expression of Smad7/TGF- $\beta$ pathway-associated proteins is downregulated in the nasal tissue of $A R$ mice. First, the dose response profile of TGP effect on the development of AR was assessed. TGP treatment relieved serum IgE, eosinophil count and nasal symptoms (sneezing and rubbing) in AR mice in a dose-dependent manner (Fig. S1). Thus, $60 \mathrm{mg} / \mathrm{kg}$ TGP was selected as the best concentration for subsequent experiments.

To investigate the role of the Smad7TGF- $\beta$ pathway in AR, an AR mouse model was constructed (Fig. 1A). Immunofluorescence assay demonstrated that Smad7 expression was decreased and TGF- $\beta$ expression was increased in the AR group compared with the Con group (Fig. 1B). Protein expression levels of Smad7 were decreased and those of TGF- $\beta$ were enhanced in the nasal mucosa of AR mice, as shown by immunohistochemistry and western blot analysis (Fig. 1C and D). These data indicated that expression of Smad7 was upregulated and that of TGF- $\beta$ was downregulated in the nasal tissue of AR mice. 
A
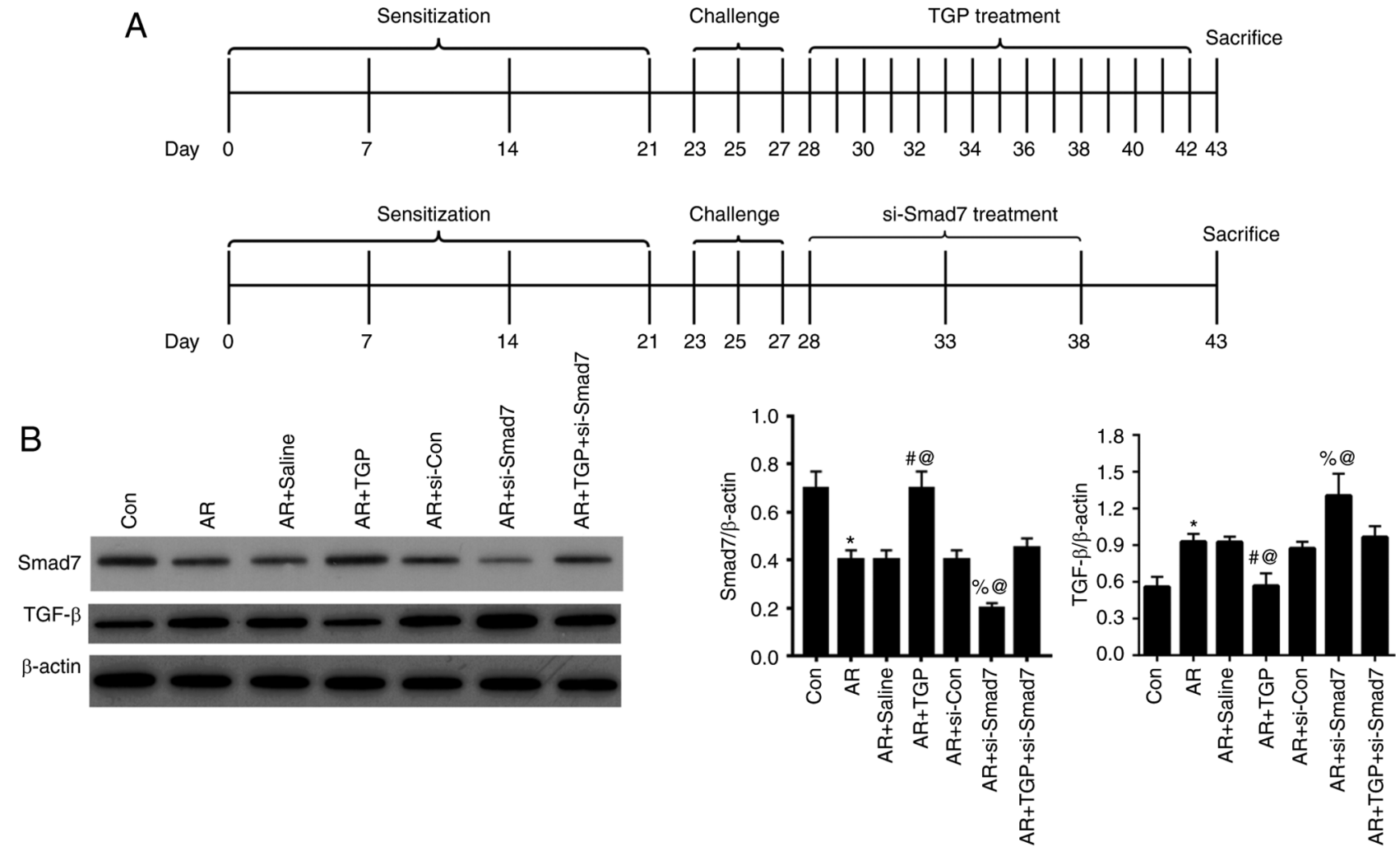

Figure 2. TGP regulation of the Smad7/TGF- $\beta$ pathway in nasal tissue of AR mice. (A) Schematic diagram of the experimental treatment group design and protocol for AR mice. (B) Protein expression levels of Smad7 and TGF- $\beta$ were measured by western blot analysis. " $\mathrm{P}<0.05$ vs. Con; " $\mathrm{P}<0.05$ vs. AR $+\mathrm{Saline}$; ${ }^{\%} \mathrm{P}<0.05$ vs. AR + si-Con; ${ }^{\circledR} \mathrm{P}<0.05$ vs. AR + TGP + si-Smad7. Smad7, Sma- and Mad-related protein 7; AR, allergic rhinitis; Con, control; si, small interfering; TGP, total glucosides of paeony.

TGP upregulates the Smad7/TGF- $\beta$ pathway in nasal tissue of AR mice. The effects of TGP on the Smad7/TGF- $\beta$ pathway in AR mice were investigated. The treatment protocol (TGP and si-Smad7) of AR model mice is shown in Fig. 2A. Following nasal cavity challenge, AR mice were treated with TGP on days 28-42 and/or si-Smad7 on days 28, 33 and 38. Finally, on day 43, mice were sacrificed. Protein expression levels of Smad7 and TGF- $\beta$ were detected by western blot analysis. The decreased expression of Smad7 induced by AR was reversed in the AR + TGP group but further decreased in the AR + si-Smad7 group; this effect was partially restored in the AR + TGP + si-Smad7 group. Enhanced expression of TGF- $\beta$ induced by AR was rescued in the AR + TGP group but further increased in the AR + si-Smad7 group; this effect was partially restored in the AR + TGP + si-Smad7 group (Fig. 2B). Taken together, these findings indicated that TGP regulated the Smad7/TGF- $\beta$ pathway in the nasal tissue of AR mice.

TGP alleviates increased serum IgE, nasal symptoms and histopathological changes in AR mice. The increased serum IgE concentration induced by AR was attenuated in the $\mathrm{AR}+\mathrm{TGP}$ group but further enhanced in the AR + si-Smad7 group; this effect was reversed in AR + TGP + si-Smad7 group (Fig. 3A). The aggravated nasal symptoms (sneezing and rubbing) induced by AR were lessened in the AR + TGP group but further increased in the AR + si-Smad7 group; this effect was partially reversed in the AR + TGP + si-Smad7 group (Fig. 3B and C). The increased number of eosinophil, goblet cell count and percentage of collagen fibers induced by AR were decreased in the AR + TGP group but further increased in the AR + si-Smad7 group; this effect was rescued in the AR + TGP + si-Smad7 group (Fig. 3D). These data suggested that TGP decreased serum IgE concentration, nasal symptoms and histopathological changes in AR mice.

TGP alleviates oxidative stress in AR mice. Next, the effects of TGP on oxidative stress in AR mice were determined. The increased MDA induced by AR in the blood was decreased in the $\mathrm{AR}+\mathrm{TGP}$ group but further heightened in the AR + si-Smad7 group; this effect was rescued in the AR + TGP + si-Smad7 group (Fig. 4A). The weakened blood levels of GSH, SOD and CAT caused by AR were enhanced in the + TGP group but further decreased in the AR + si-Smad7 group; this effect was partially restored in the AR + TGP + si-Smad7 group (Fig. 4B-D). The enhanced MDA levels resulting from AR in nasal mucosa were decreased in the AR + TGP group but further increased in the AR + si-Smad7 group; this effect was reversed in the AR + TGP + si-Smad7 group (Fig. 4E). The decreased GSH, SOD and CAT levels induced by AR in the nasal mucosa were increased in the AR+ TGP group but further weakened in the AR + si-Smad7 group; this effect was reversed in the AR + TGP + si-Smad7 group (Fig. 4F-H). These results indicated that TGP ameliorated oxidative stress in AR mice.

TGP alleviates cell apoptosis in AR mice. The effects of TGP on cell apoptosis in AR mice were investigated. The increased 


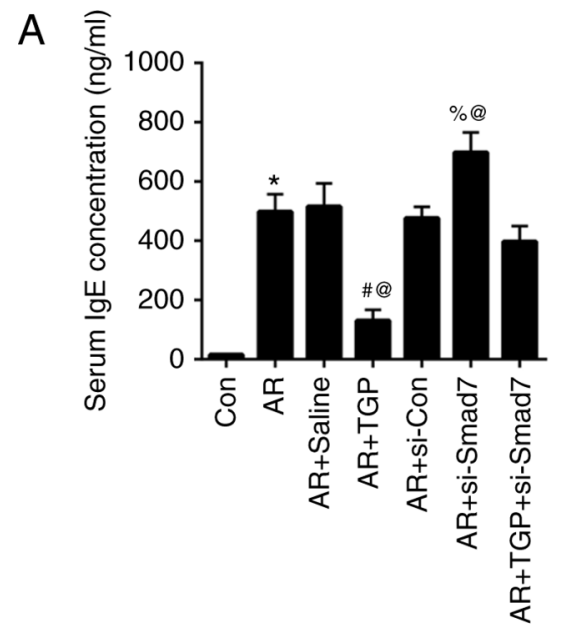

B

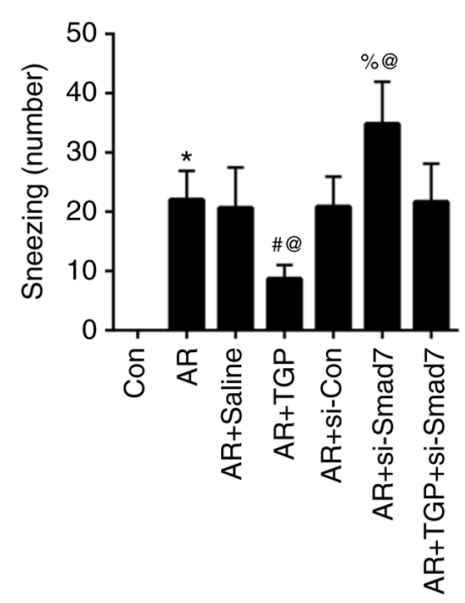

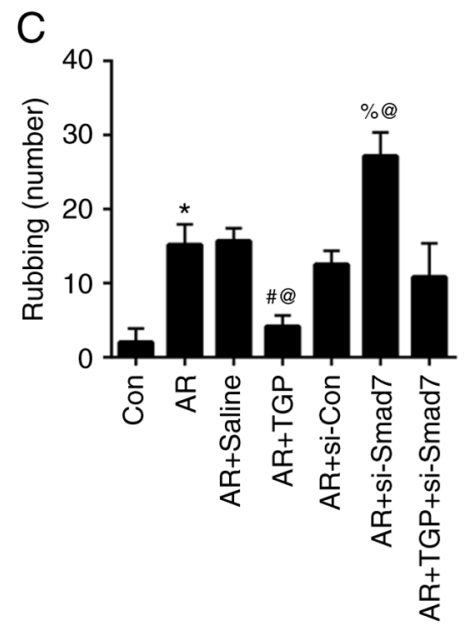
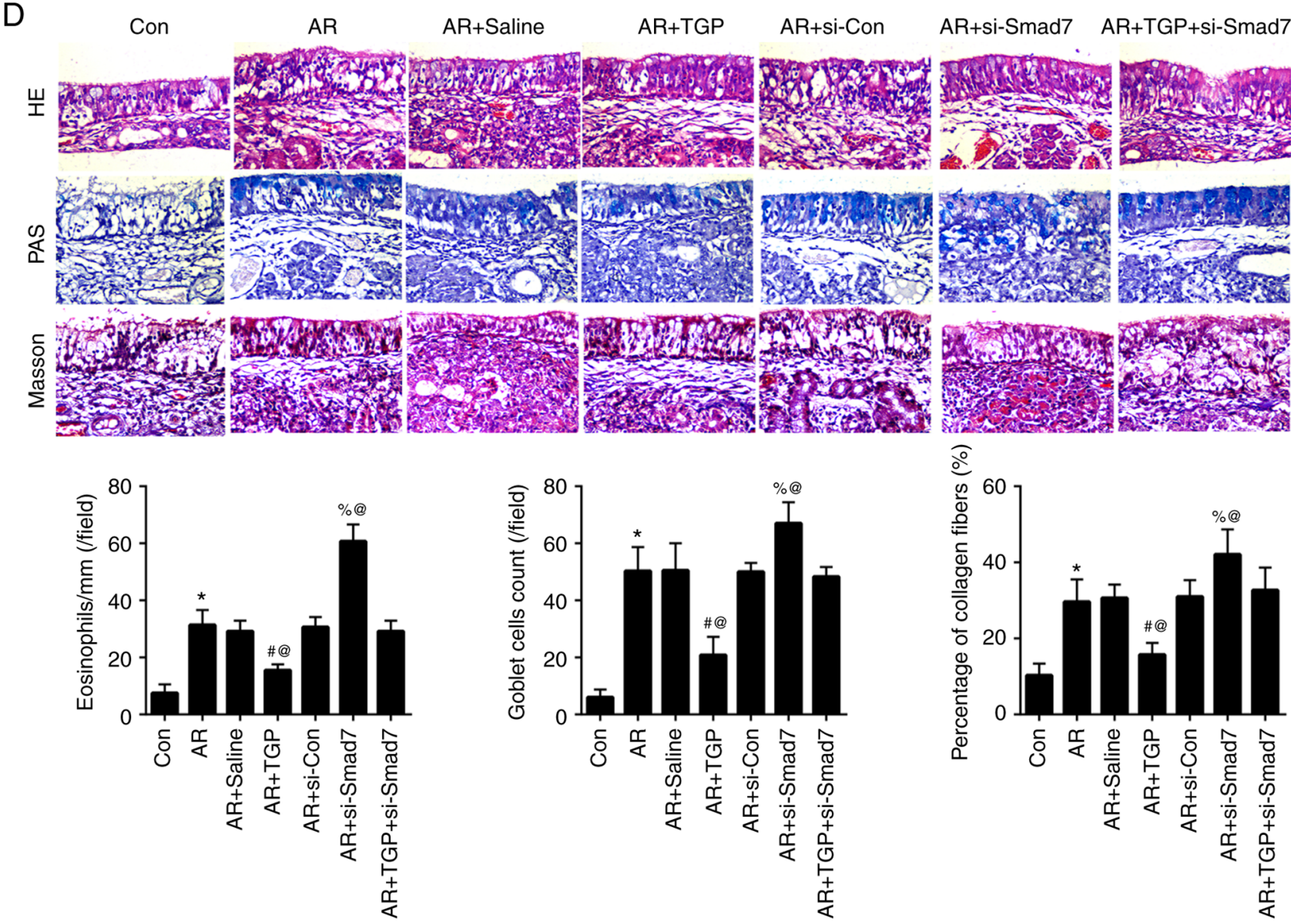

Figure 3. Effects of TGP on serum IgE, nasal symptoms and histopathological changes in AR mice. (A) IgE concentration in the blood was determined by ELISA. (B) Sneezing and (C) rubbing frequency were observed in AR mice for $30 \mathrm{~min}$. (D) Level of eosinophils, goblet cell count and percentage of collagen fibers were determined by HE, PAS and Masson staining, respectively (magnification, $x 500$ ). ${ }^{*} \mathrm{P}<0.05$ vs. Con; ${ }^{*} \mathrm{P}<0.05$ vs. AR + Saline; ${ }^{\%} \mathrm{P}<0.05$ vs. AR + si-Con; ${ }^{\circledR} \mathrm{P}<0.05$ vs. AR + TGP + si-Smad7. Smad7, Sma- and Mad-related protein 7; AR, allergic rhinitis; Con, control; si, small interfering; TGP, total glucosides of paeony; HE, hematoxylin-eosin; PAS, period acid-Schiff.

cell apoptosis induced by AR was lessened in the AR + TGP group but further enhanced in the AR + si-Smad7 group; this effect was partially restored in the $\mathrm{AR}+\mathrm{TGP}+\mathrm{si}-\mathrm{Smad} 7$ group (Fig. 5A and B). In addition, decreased Bcl-2 expression levels induced by AR were enhanced in the AR + TGP group but further weakened in the AR + si-Smad7 group; this effect was reversed in the AR + TGP + si-Smad7 group. The increased Bax and Cleaved-caspase 3 expression levels caused by AR were decreased in the AR + TGP group but further enhanced in the AR + si-Smad7 group; this effect was reversed in the AR + TGP + si-Smad7 group (Fig. 5C-F). These findings indicated that TGP ameliorated cell apoptosis in AR mice.

TGP alleviates inflammatory response in AR mice. Lastly, the effect of TGP on inflammatory response in AR mice was 
A

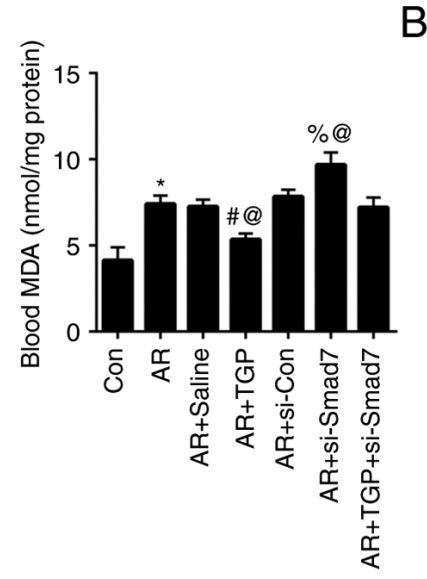

E

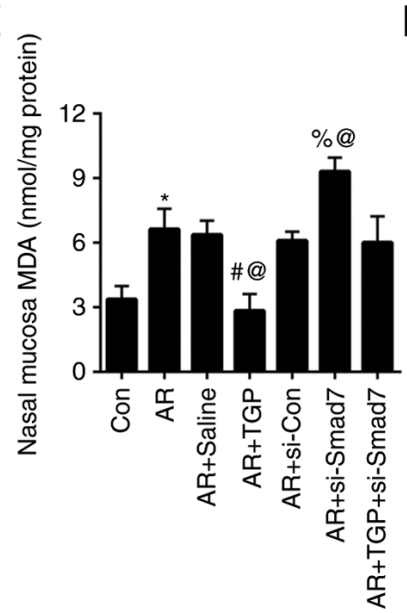

B

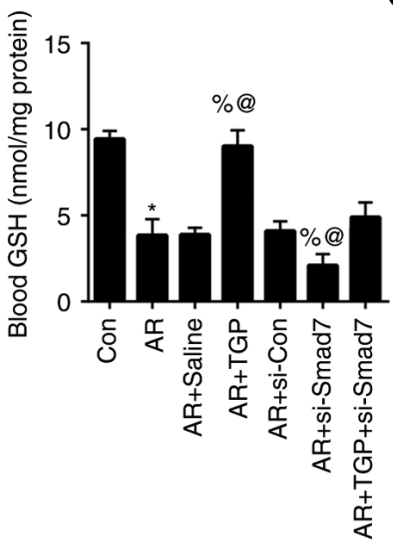

C

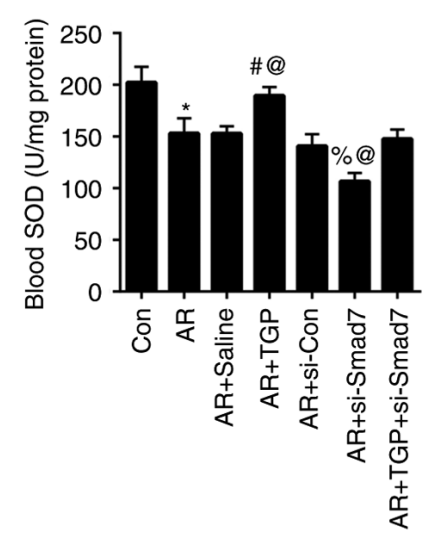

D

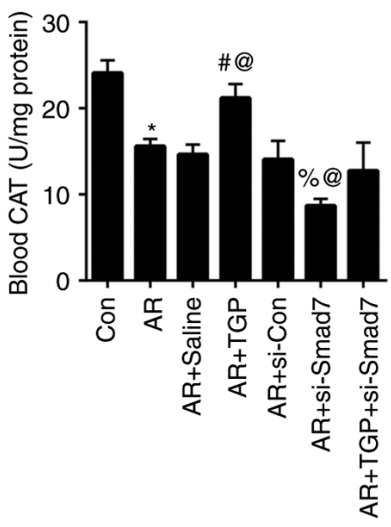

F

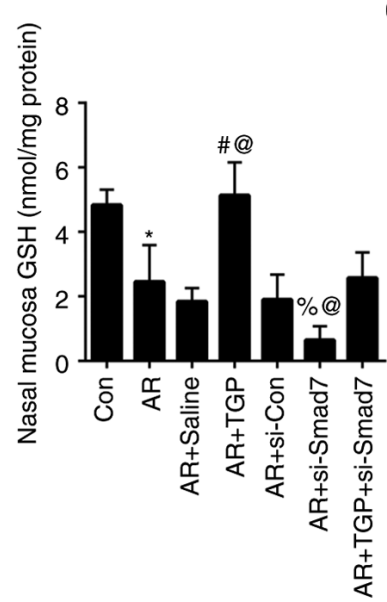

G

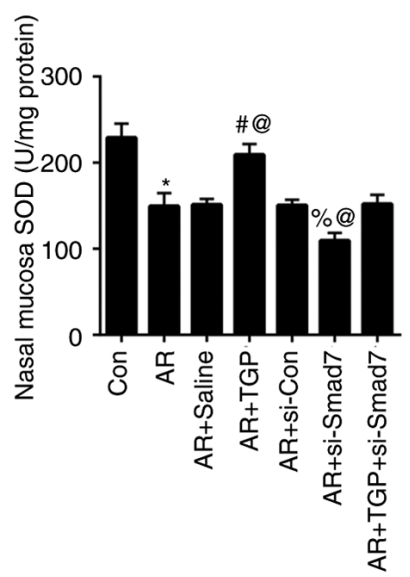

$\mathrm{H}$

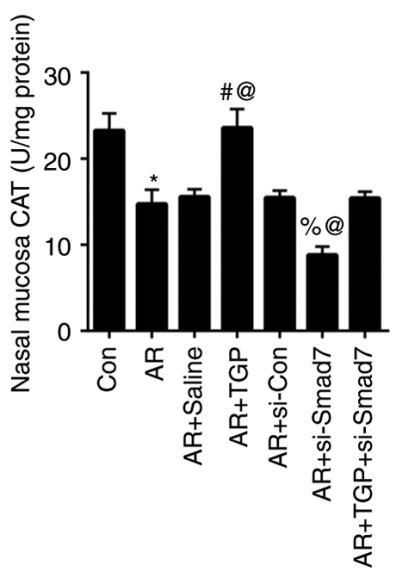

Figure 4. Effects of TGP on oxidative stress in AR mice. Levels of (A) MDA, (B) GSH, (C) SOD and (D) CAT were measured in the blood of AR mice. Levels of (E) MDA, (F) GSH, (G) SOD and (H) CAT were measured in the nasal mucosa of AR mice. ${ }^{*} \mathrm{P}<0.05$ vs. Con; ${ }^{\#} \mathrm{P}<0.05$ vs. AR $+\mathrm{Saline}$; ${ }^{\mathrm{P}}<0.05$ vs. AR + si-Con; ${ }^{\circledR} \mathrm{P}<0.05$ vs. AR + TGP + si-Smad7. Smad7, Sma- and Mad-related protein 7; AR, allergic rhinitis; Con, control; si, small interfering; TGP, total glucosides of paeony; MDA, malondialdehyde; GSH, glutathione; SOD, superoxide dismutase; CAT, catalase.

investigated. ELISA demonstrated that increased levels of IL-4, IL-5, IL-17 and IFN- $\gamma$ caused by AR were decreased in the $\mathrm{AR}+\mathrm{TGP}$ group but further increased in the AR + si-Smad7 group; this effect was reversed in the AR + TGP + si-Smad7 group (Fig. 6A-D). Similar changes in protein levels of IL-4, IL-5, IL-17 and IFN- $\gamma$ were also detected by western blot analysis (Fig. E-I). These findings demonstrated that TGP ameliorated the inflammatory response in AR mice.

\section{Discussion}

$\mathrm{AR}$ is an allergen-induced allergic inflammatory response in the nasal mucosa that is initiated by release of IgE-mediated mediators and involves a variety of immunoreactive cells and cytokines including, Th2 lymphocytes, M2a macrophages and IL-4 (24-26). The Smad7/TGF- $\beta$ signaling pathway is not only involved in regulation of numerous types of disease, including spinal cord ischemia reperfusion, anaplastic thyroid cancer and pancreatic cancer $(22,27,28)$, but has also been reported to be associated with AR processes (21). In the present study, expression of Smad7 was upregulated and that of TGF- $\beta$ was downregulated in the nasal tissue of AR mice.

TGP is the primary active ingredient of Paeonia lactiflora Pall. and exerts anti-inflammation, anti-oxidation and analgesic effects $(12,29)$. In recent years, it has been reported that TGP has numerous immunomodulatory effects in various types of disease, including rheumatoid arthritis, autoimmune hepatitis and Sjögren's syndrome (SS) (30-32). Therefore, the present study aimed to determine the role of TGP in AR. TGP regulated the Smad7/TGF- $\beta$ pathway in nasal tissue of AR mice by upregulating Smad7 and downregulating TGF- $\beta$. Moreover, TGP relieved serum IgE, nasal symptoms and histopathological changes in AR mice.

Oxidative stress refers to the imbalance between production of oxygen free radicals and endogenous antioxidants that offset their harmful effects, resulting in irreversible tissue damage $(33,34)$. Oxygen free radicals interact with DNA, proteins and lipids, inducing conformational changes of cell structures and causing cellular derangement and dysfunction (35). Oxidative stress is a key feature in the pathology of AR (36-38). The present study demonstrated that TGP ameliorated oxidative stress in AR mice by decreasing MDA levels and enhancing GSH, SOD and CAT levels.

Cell apoptosis refers to spontaneous and orderly death of cells to maintain homeostasis, involving the activation, expression and regulation of a series of genes including Bax and Bcl-2 $(39,40)$. Cell apoptosis is a key process in $\mathrm{AR}$ that is regulated by numerous factors. For example, 
A Con
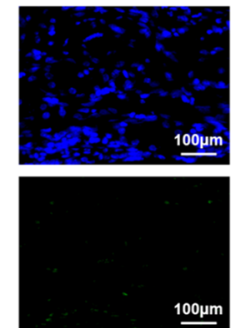

100pm

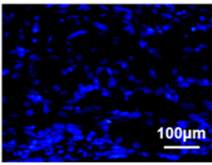

$100 \mu \mathrm{m}$

$\mathrm{B}$
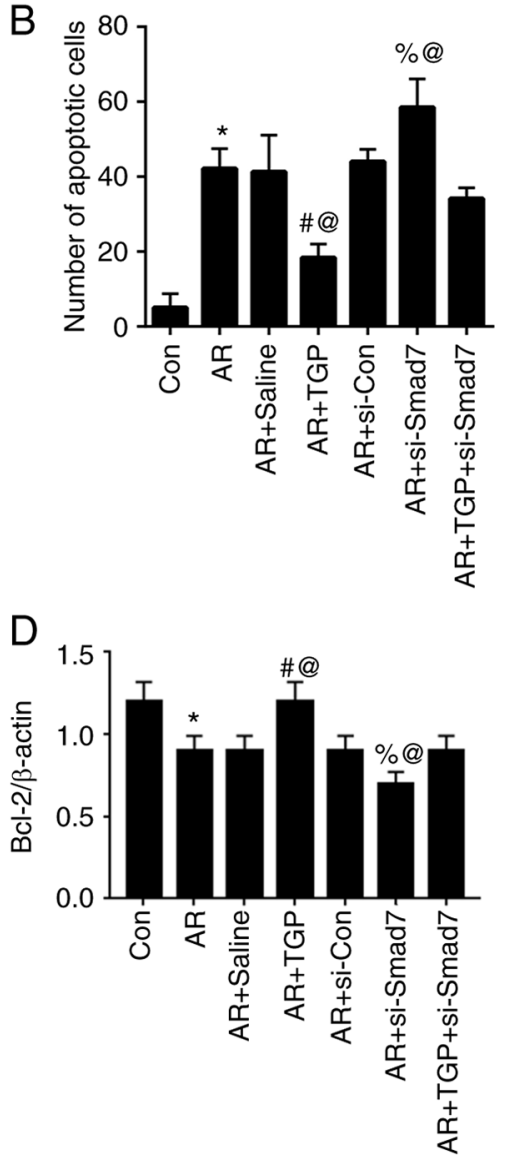
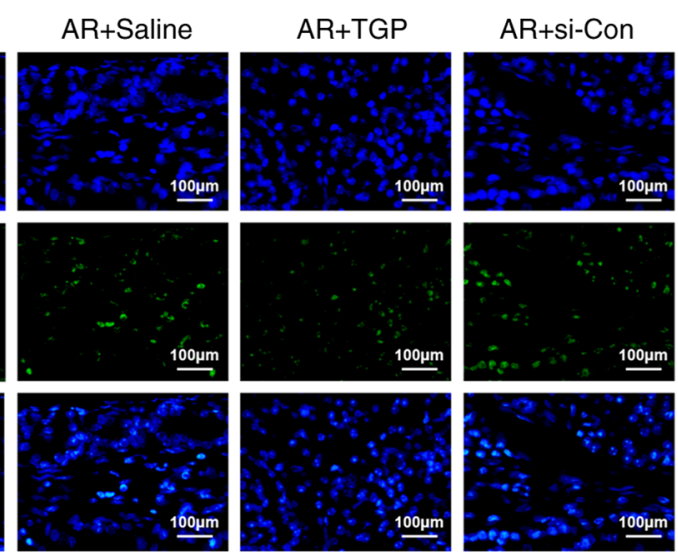

$100 \mu \mathrm{m}$

C

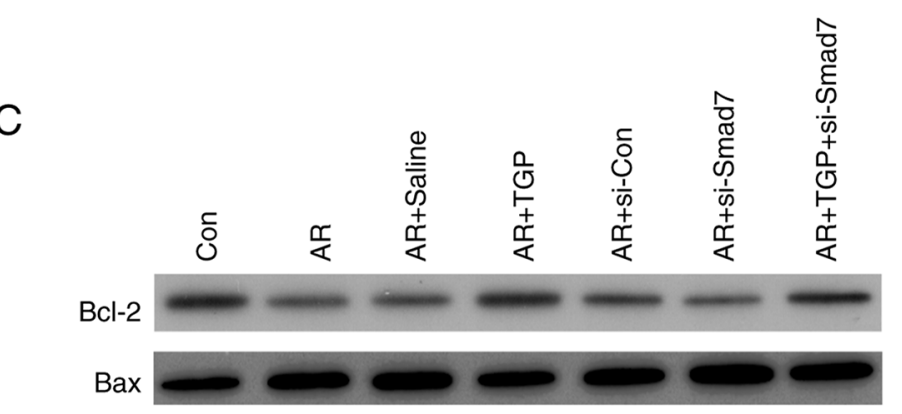

Cleaved caspase-3

$\beta$-actin
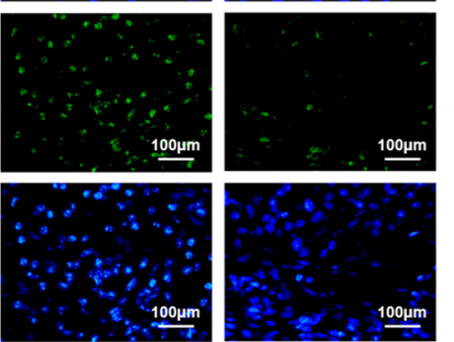

100pm

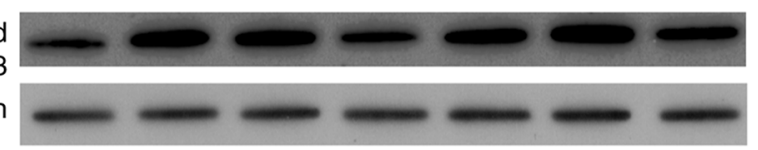

$\mathrm{E}$

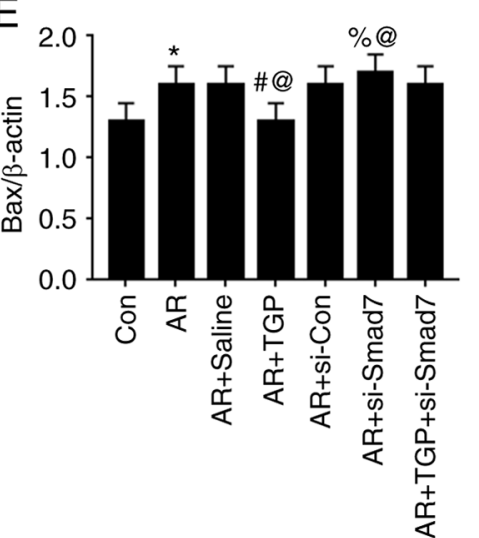

$\mathrm{F}$

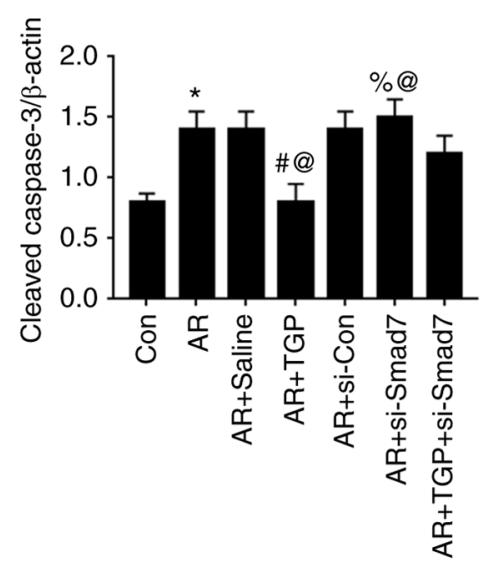

Figure 5. Effects of TGP on cell apoptosis in AR mice. (A and B) Cell apoptosis was detected by TUNEL assay (Scale bar, $200 \mu \mathrm{m})$. (C) Protein expression levels of (D) Bcl-2, (E) Bax and (F) Cleaved-caspase 3 were determined by western blot analysis. ${ }^{*} \mathrm{P}<0.05$ vs. Con; ${ }^{\#} \mathrm{P}<0.05$ vs. AR $+\mathrm{Saline} ;{ }^{\%} \mathrm{P}<0.05$ vs. AR + si-Con; ${ }^{\circledR} \mathrm{P}<0.05$ vs. AR + TGP + si-Smad7. Smad7, Sma- and Mad-related protein 7; AR, allergic rhinitis; Con, control; si, small interfering; TGP, total glucosides of paeony.

inactivation of the PD-1/PD-L1 pathway increases apoptosis of $\mathrm{CD} 19^{+} \mathrm{CD} 25^{+} \mathrm{B}$ regulatory cells and inhibits secretion of IL-10 in patients with AR (41). MicroRNA (miR)-375 suppresses the JAK2/STAT3 pathway to decrease nasal mucosa cell apoptosis and relieve AR (8). Tumor necrosis factor $\alpha$ and IL-5 regulate the apoptosis rate of olfactory sphere cells to weaken olfactory regeneration in AR mice (42). In the present study, TGP downregulated Bax and Cleaved-caspase 3, but upregulated Bcl-2 to ameliorate cell apoptosis in AR mice.
In the later stage of AR, inflammatory cells (primarily eosinophil granulocytes) accumulate in the nasal polyps and secrete cytokines and inflammatory mediators, such as IgE, IL-4, IL-5, IL-17 and IFN- $\gamma$, which serve an important role in the development of local inflammation (43). miR-345-5p affects the Toll-like receptor $4 / \mathrm{NF}-\kappa \mathrm{B}$ pathway in AR by serving as an anti-inflammatory regulator (44). Adrenoreceptor $\beta 2$ inhibits AR inflammatory cytokine production induced by IL-13 (45). IL-37 suppresses the C-C motif chemokine ligand 11 signaling pathway to alleviate 


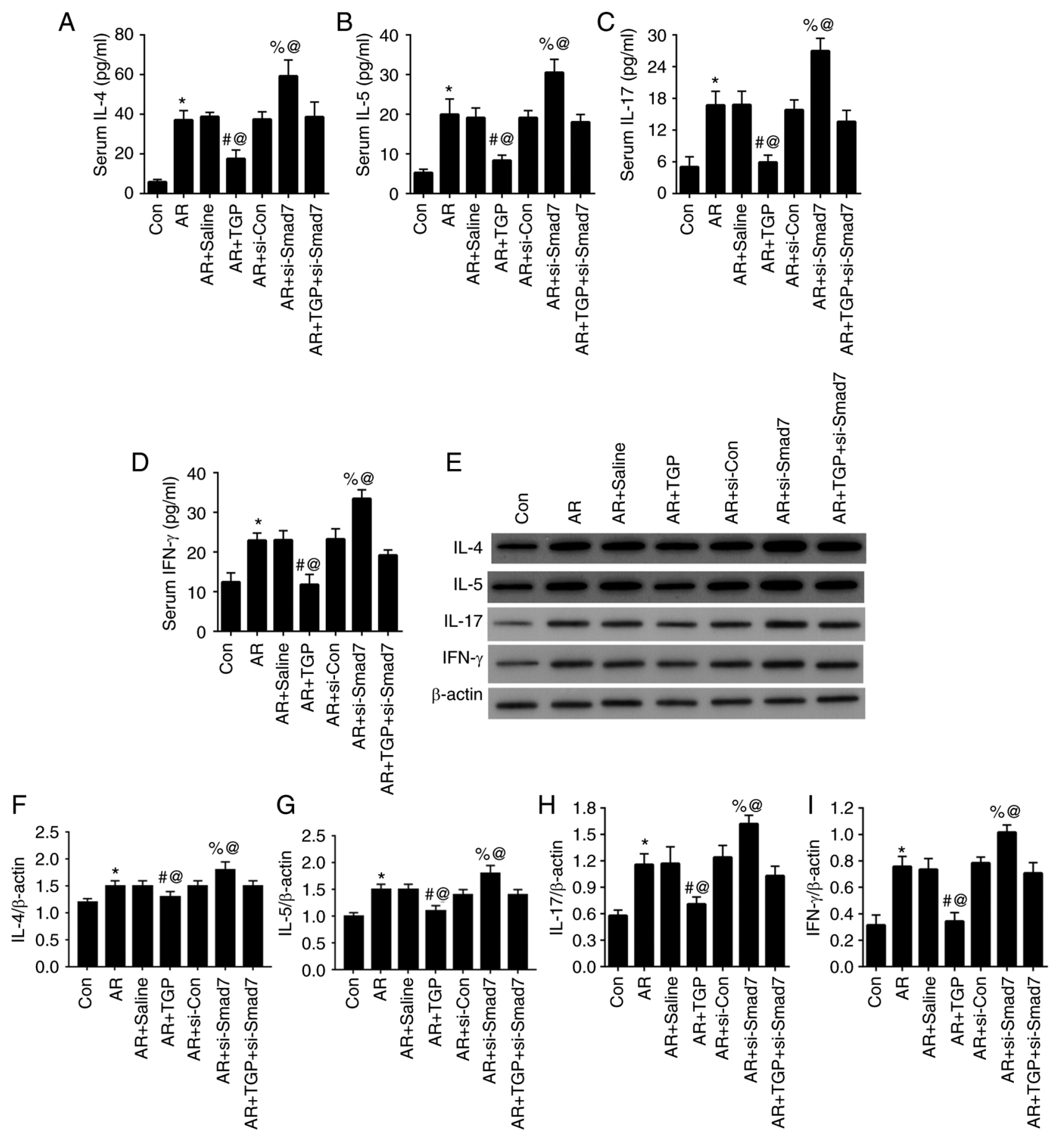

Figure 6. Effects of TGP on inflammatory response in AR mice. Levels of (A) IL-4, (B) IL-5, (C) IL-17 and (D) IFN- $\gamma$ were measured by ELISA. (E) Protein expression levels of (F) IL-4, (G) IL-5, (H) IL-17 and (I) IFN- $\gamma$ were measured by western blot analysis. " $\mathrm{P}<0.05$ vs. Con; ${ }^{\text {P }}<0.05$ vs. AR + Saline; ${ }^{\%} \mathrm{P}<0.05$ vs. AR + si-Con; ${ }^{\circledR} \mathrm{P}<0.05$ vs. AR + TGP + si-Smad7. Sma- and Mad-related protein 7; AR, allergic rhinitis; Con, control; si, small interfering; TGP, total glucosides of paeony.

allergic inflammation in AR mice (46). The present study verified that TGP ameliorated the inflammatory response in AR mice by decreasing IL-4, IL-5, IL-17 and IFN- $\gamma$ levels. Smad7 inhibition aggravated the symptoms of AR mice via activation of the TGF- $\beta$ pathway and reversed the protective effect of TGP in AR mice.

There are certain limitations in the present study. Although TGP significantly inhibited inflammatory cytokine levels in plasma of AR mice, levels of inflammatory cytokines in nasal lavage fluid or mucosal extract were not investigated. TPG contains $>15$ monoterpene glycosides; however, the most effective component of TGP to alleviate AR is still unknown. Paeoniflorin and albiflorin are the most abundant ingredients and account for the pharmacological effects observed for TPG in both in vitro and in vivo studies (47-49). Therefore, it was speculated that paeoniflorin and albiflorin may be effective components of TGP in inhibiting AR; however, further investigations are required.

In summary, the present study demonstrated that TGP ameliorated oxidative stress, apoptosis and inflammatory response by regulating the Smad7/TGF- $\beta$ pathway in AR. 


\section{Acknowledgements}

Not applicable.

\section{Funding}

No funding was received.

\section{Availability of data and materials}

The datasets used and/or analyzed during the current study are available from the corresponding author on reasonable request.

\section{Authors' contributions}

YJ was responsible for study concept and design and drafting the manuscript. AZ performed experiments, analyzed and collected data and reviewed the manuscript. All authors have read and approved the final manuscript. YJ and AZ confirm the authenticity of all the raw data.

\section{Ethics approval and consent to participate}

All experimental procedures performed on animals in this study were based on the National Institutes of Health Guide for the Care and Use of Laboratory Animals. The study was approved by the Institutional Animal Care and Use Committee (approval no. AWE2020030601).

\section{Patient consent for publication}

Not applicable.

\section{Competing interests}

The authors declare that they have no competing interests.

\section{References}

1. Al Suleimani YM and Walker MJ: Allergic rhinitis and its pharmacology. Pharmacol Ther 114: 233-260, 2007.

2. Cheng L, Chen J, Fu Q, He S, Li H, Liu Z, Tan G, Tao Z, Wang D, Wen W, et al: Chinese society of allergy guidelines for diagnosis and treatment of allergic rhinitis. Allergy Asthma Immunol Res 10: 300-353, 2018.

3. Kakli HA and Riley TD: Allergic Rhinitis. Prim Care 43: 465-475, 2016

4. Zhang L, Han D, Huang D, Wu Y, Dong Z, Xu G, Kong W and Bachert C: Prevalence of self-reported allergic rhinitis in eleven major cities in China. Int Arch Allergy Immunol 149: 47-57, 2009.

5. Bao Y, Chen J, Cheng L, Guo Y, Hong S, Kong W, Lai H, Li H, Li H, Li J, et al: Chinese Guideline on allergen immunotherapy for allergic rhinitis. J Thorac Dis 9: 4607-4650, 2017.

6. Du K, Qing H, Zheng M, Wang X and Zhang L: Intranasal antihistamine is superior to oral $\mathrm{H}_{1}$ antihistamine as an add-on therapy to intranasal corticosteroid for treating allergic rhinitis. Ann Allergy Asthma Immunol 125: 589-596.e3, 2020.

7. McColl A, Michlewska S, Dransfield I, Dransfield I and Rossi AG: Effects of glucocorticoids on apoptosis and clearance of apoptotic cells. ScientificWorldJournal 7: 1165-1181, 2007.

8. Mims JW: Epidemiology of allergic rhinitis. Int Forum Allergy Rhinol 4 (Suppl 2): S18-S20, 2014.

9. Ahmadiafshar A and Ahmadiafshar S: Efficacy and safety of inhaled and intranasal corticosteroids. Antiinflamm Antiallergy Agents Med Chem 13: 83-87, 2014.
10. Wheatley LM and Togias A: Clinical practice. Allergic rhinitis. N Engl J Med 372: 456-463, 2015.

11. Hossenbaccus L, Linton S, Garvey S and Ellis AK: Towards definitive management of allergic rhinitis: Best use of new and established therapies. Allergy Asthma Clin Immunol 16: 39, 2020.

12. Jiang H, Li J, Wang L, Wang S, Nie X, Chen Y, Fu Q, Jiang M, Fu C and He Y: Total glucosides of paeony: A review of its phytochemistry, role in autoimmune diseases, and mechanisms of action. J Ethnopharmacol 258: 112913, 2020.

13. Huang XT, Wang B, Zhang WH, Peng MQ and Lin D: Total glucosides of paeony suppresses experimental autoimmune uveitis in association with inhibition of Th1 and Th2 cell function in mice. Int J Immunopathol Pharmacol 32: 394632017751547, 2018.

14. Lin J, Xiao L, Ouyang G, Shen Y, Huo R, Zhou Z, Sun Y, Zhu X, Zhang J, Shen B and Li N: Total glucosides of paeony inhibits Th1/Th17 cells via decreasing dendritic cells activation in rheumatoid arthritis. Cell Immunol 280: 156-163, 2012.

15. Zhou L, Cao T, Wang Y, Yao H, Du G, Tian Z and Tang G: Clinical observation on the treatment of oral lichen planus with total glucosides of paeony capsule combined with corticosteroids. Int Immunopharmacol 36: 106-110, 2016.

16. Zhou Y, Jin L, Kong F, Zhang H, Fang X, Chen Z, Wang G, $\mathrm{Li} \mathrm{X}$ and Li X: Clinical and immunological consequences of total glucosides of paeony treatment in Sjögren's syndrome: A randomized controlled pilot trial. Int Immunopharmacol 39: 314-319, 2016.

17. Berker M, Frank LJ, Geßner AL, Grassl N, Holtermann AV, Höppner S, Kraef C, Leclaire MD, Maier P, Messerer DA, et al: Allergies-A T cells perspective in the era beyond the $\mathrm{T}_{\mathrm{H}} 1 / \mathrm{T}_{\mathrm{H}} 2$ paradigm. Clin Immunol 174: 73-83, 2017.

18. Eifan AO and Durham SR: Pathogenesis of rhinitis. Clin Exp Allergy 46: 1139-1151, 2016.

19. Sporn MB and Roberts AB: Transforming growth factor-beta: Recent progress and new challenges. J Cell Biol 119: 1017-1021, 1992.

20. Lawrence DA: Transforming growth factor-beta: A general review. Eur Cytokine Netw 7: 363-374, 1996.

21. Salib RJ, Kumar S, Wilson SJ and Howarth PH: Nasal mucosal immunoexpression of the mast cell chemoattractants TGF-beta, eotaxin, and stem cell factor and their receptors in allergic rhinitis. J Allergy Clin Immunol 114: 799-806, 2004.

22. Xie L, Yu S, Yang K, Li C and Liang Y: Hydrogen sulfide inhibits autophagic neuronal cell death by reducing oxidative stress in spinal cord ischemia reperfusion injury. Oxid Med Cell Longev 2017: 8640284, 2017.

23. Chaudhury D, Walsh JJ, Friedman AK, Juarez B, Ku SM, Koo JW, Ferguson D, Tsai HC, Pomeranz L, Christoffel DJ, et al: Rapid regulation of depression-related behaviours by control of midbrain dopamine neurons. Nature 493: 532-536, 2013.

24. Naclerio RM, Meier HL, Kagey-Sobotka A, Adkinson NF Jr, Meyers DA, Norman PS and Lichtenstein LM: Mediator release after nasal airway challenge with allergen. Am Rev Respir Dis 128: 597-602, 1983.

25. Zhang Y, Lan F and Zhang L: Advances and highlights in allergic rhinitis. Allergy 76: 3383-3389, 2021.

26. Geng B, Dilley M and Anterasian C: Biologic therapies for allergic rhinitis and nasal polyposis. Curr Allergy Asthma Rep 21: 36, 2021.

27. Jiao C, Li L, Zhang P, Zhang L, Li K, Fang R, Yuan L, Shi K, Pan L, Guo Q, et al: REGY ablation impedes dedifferentiation of anaplastic thyroid carcinoma and accentuates radio-therapeutic response by regulating the Smad7-TGF- $\beta$ pathway. Cell Death Differ 27: 497-508, 2020

28. Zhu Z, Xu Y, Zhao J, Liu Q, Feng W, Fan J and Wang P: MiR-367 promotes epithelial-to-mesenchymal transition and invasion of pancreatic ductal adenocarcinoma cells by targeting the Smad7-TGF- $\beta$ signalling pathway. Br J Cancer 112: 1367-1375, 2015.

29. Zhang L, Yu J, Wang C and Wei W: The effects of total glucosides of paeony (TGP) and paeoniflorin (Pae) on inflammatory-immune responses in rheumatoid arthritis (RA). Funct Plant Biol 46: 107-117, 2019.

30. Liu G, Wang Z, Li X, Liu R, Li B, Huang L, Chen Y, Zhang C, Zhang H, Li Y, et al: Total glucosides of paeony (TGP) alleviates constipation and intestinal inflammation in mice induced by SjC6gren's syndrome. J Ethnopharmacol 260: 113056, 2020.

31. Chen H, Wen Y, Pan T and Xu S: Total glucosides of paeony improve complete freund's adjuvant-induced rheumatoid arthritis in rats by inhibiting toll-like receptor 2-mediated tumor necrosis factor receptor-associated factor 6/nuclear factor-kappa B pathway activation. J Tradit Chin Med 39: 566-574, 2019. 
32. Shen M, Men R, Fan X, Wang T, Huang C, Wang H, Ye T, Luo X and Yang L: Total glucosides of paeony decreases apoptosis of hepatocytes and inhibits maturation of dendritic cells in autoimmune hepatitis. Biomed Pharmacother 124: 109911, 2020.

33. Sies H: Oxidative stress: A concept in redox biology and medicine. Redox Biol 4: 180-183, 2015.

34. Hybertson BM, Gao B, Bose SK and McCord JM: Oxidative stress in health and disease: The therapeutic potential of $\mathrm{Nrf} 2$ activation. Mol Aspects Med 32: 234-246, 2011.

35. Burton GJ and Jauniaux E: Oxidative stress. Best Pract Res Clin Obstet Gynaecol 25: 287-299, 2011.

36. Sim CS, Lee JH, Kim SH, Han MW, Kim Y, Oh I, Yun SC and Lee JC: Oxidative stress in schoolchildren with allergic rhinitis: Propensity score matching case-control study. Ann Allergy Asthma Immunol 115: 391-395, 2015.

37. Celik M, Tuncer A, Soyer OU, Sac'kesen C, Tanju Besler H and Kalayci O: Oxidative stress in the airways of children with asthma and allergic rhinitis. Pediatr Allergy Immunol 23 556-561, 2012

38. Wei Choo CY, Yeh KW, Huang JL, Su KW, Tsai MH, Hua MC, Liao SL, Lai SH, Chen LC and Chiu CY: Oxidative stress is associated with atopic indices in relation to childhood rhinitis and asthma. J Microbiol Immunol Infect 54: 466-473, 2021.

39. Xu X, Lai Y and Hua ZC: Apoptosis and apoptotic body: Disease message and therapeutic target potentials. Biosci Rep 39 BSR20180992, 2019.

40. Du L, Meng Q, Chen Y and Wu P: Subcellular location prediction of apoptosis proteins using two novel feature extraction methods based on evolutionary information and LDA. BMC Bioinformatics 21: 212, 2020.

41. Wang ZA and Tan F: The blockade of PD-1/PD-L1 pathway promotes the apoptosis of $\mathrm{CD} 19^{+} \mathrm{CD} 25^{+}$Bregs and suppresses the secretion of IL-10 in patients with allergic rhinitis. Scand J Immunol 91: e12836, 2020.
42. Kim DK, Choi SA, Eun KM, Kim SK, Kim DW and Phi JH: Tumour necrosis factor alpha and interleukin-5 inhibit olfactory regeneration via apoptosis of olfactory sphere cells in mice models of allergic rhinitis. Clin Exp Allergy 49: 1139-1149, 2019.

43. Ventura MT, Bruno LM, Iacobelli A and Tursi A: Eosinophils in allergic diseases: Immunopharmacological regulation. Immunopharmacol Immunotoxicol 19: 405-423, 1997.

44. Liu J, Jiang Y, Han M, Jiang L, Liang D, Li S, Xu Z, Wang L and Li N: MicroRNA-345-5p acts as an anti-inflammatory regulator in experimental allergic rhinitis via the TLR4/NF- $\kappa B$ pathway. Int Immunopharmacol 86: 106522, 2020.

45. Wang L, Lv Q, Song X, Jiang K and Zhang J: ADRB2 suppresses IL-13-induced allergic rhinitis inflammatory cytokine regulated by miR-15a-5p. Hum Cell 32: 306-315, 2019.

46. Lei H, Sun Y and Quan S: IL-37 relieves allergic inflammation by inhibiting the CCL11 signaling pathway in a mouse model of allergic rhinitis. Exp Ther Med 20: 3114-3121, 2020.

47. Xu W, Zhao Y, Qin Y, Ge B, Gong W, Wu Y, Li X, Zhao Y, Xu P and Xue M: Enhancement of exposure and reduction of elimination for paeoniflorin or albiflorin via co-administration with total peony glucosides and hypoxic pharmacokinetics comparison. Molecules 21: 874, 2016.

48. Tabata K, Matsumoto K, Murakami $\mathrm{Y}$ and Watanabe $\mathrm{H}$ : Ameliorative effects of paeoniflorin, a major constituent of peony root, on adenosine A1 receptor-mediated impairment of passive avoidance performance and long-term potentiation in the hippocampus. Biol Pharm Bull 24: 496-500, 2001.

49. Chen DM, Xiao L, Cai X, Zeng R and Zhu XZ: Involvement of multitargets in paeoniflorin-induced preconditioning. J Pharmacol Exp Ther 319: 165-180, 2006.

This work is licensed under a Creative Commons Attribution-NonCommercial-NoDerivatives 4.0 International (CC BY-NC-ND 4.0) License. 